\title{
INFORMATIVE-THEORETICAL ANALYSIS OF THE NANOSECOND GAIN DYNAMICS IN KrF LASER AMPLIFIER
}

\author{
V. V. Datsyuk \\ Kyiv Taras Shevchenko University, Department of Physics, \\ 64 Volodymyrs'ka Str., Kyiv, UA-01033, Ukraine \\ (Received June 18, 1999; received in final form December 30, 1999)
}

\begin{abstract}
The informative-theoretical analysis is applied in order to study the nanosecond gain dynamics in a short-pulse $\mathrm{KrF}$ laser. The analytical exploration describes the effect of $\mathrm{KrF}$ vibrational relaxation on the laser characteristics. Simple formulas are obtained for the internal efficiency of the laserlevel production and the rate of the gain recovery. Though several low vibrational levels of $\operatorname{KrF}(\mathrm{B})$ contribute to the light amplification, the energy transfer processes between these levels are found not to affect the laser characteristics noticeably.

Key words: $\mathrm{KrF}$, excimer, molecular dynamics.
\end{abstract}

PACS number(s): 33.70.Fd, 42.55.Gp, 82.20.Rp, 33.10.Gx

\section{INTRODUCTION}

The KrF laser is a widely used UV laser emitting emission with a wavelength of $0.248 \mu \mathrm{m}$ [1]. At present, the interest to this coherent emission source increased drastically due to its application in the world's semiconductor industry for integrated circuits production.

This research was stimulated by the fact that investigators of the excimer lasers did not sometimes understand the relations between the measured laser characteristics and fundamental kinetic parameters. One of the important laser characteristics is the nanosecond time of the gain recovery $t_{s}$ after the saturation of the laser amplifier by a short light pulse [2]. The first detailed study of this quantity was fulfilled by Corcum and Taylor [3] for the XeCl laser. It was presumed that, according to the balance condition, $t_{s}$ was equal to the excimer lifetime $\tau_{u}$. However, paper [9] stated parameter $t_{s}$ to be the inverse function of the rate constant of vibrational relaxation $k_{\mathrm{VT}}: t_{s}=\tau_{v} \equiv\left(k_{\mathrm{VT}}[\mathrm{M}]\right)^{-1}$, here $[\mathrm{M}]$ is the volume density of the buffer gas. However, application of the Fokker-Planck approach yielded the equality $t_{s}=\tau_{u}$ to be valid for the $\mathrm{XeCl}$ excimers $[10,11]$.

As to the KrF laser, its upper laser level is a cluster of several vibrational levels of electronic state B. The study of the gain recovery in $\mathrm{KrF}$ laser was fulfilled in [12] with a numeric code allowing for populations of the 10 lowest vibrational levels of $\mathrm{KrF}$ (B and $\mathrm{C}$ ). The sum populations of the higher vibrational levels of $\operatorname{KrF}(\mathrm{B}$ and $\mathrm{C}$ ) were taken into account by two additional kinetic equations. It was found that the recovery time $t_{s}$ was independent of the rate constant of vibrational relaxation. However, a relation of $t_{s}$ with kinetic parameters of the $\mathrm{KrF}$ molecule was not determined.

In this paper, the net small-signal gain coefficient $g$ is calculated from nonstationary vibrational distributions of excimers. The vibrational distributions are found from the Fokker-Planck equation. In the KrF laser, several low vibrational levels contribute to the light amplification [13-15]. Of course, the contribution to the gain coef- ficient from each vibrational level must be taken into account. These contributions however are not only known with insufficient accuracy but also are changing during light pulse amplification, in accordance with the change of emission line width. To discover the most general regularities of the light amplification, the informativetheoretical analysis can be applied. In general, this method consists in the following. Definite dependences on vibrational energy are assumed to be known for some kinetic parameters. These dependences include however surprising parameters, $\lambda_{i}$. An analytical solution of the kinetic equation dependent on $\lambda_{i}$ can thereby be found. It is used further to compare the predicted and experimental quantities and better understand the molecular kinetics.

This paper is organized as follows. The method for the analytical treatment of the electronic-vibrational relaxation is described in Sec. II. In Sec. III, the informativetheoretical analysis is applied to determine the temporal dependence of the gain coefficient, $g(t)$. The predicted dependence of $g(t)$ is discussed and compared with experimental data in Sec. IV. In Sec. V, we determine the peculiarities of the upper laser level production in $\mathrm{KrF}$ laser. Finally, concluding remarks are given in Sec. VI.

\section{THEORY OF KrF VIBRATIONAL RELAXATION}

Below the model of vibrational relaxation $[16,17]$ is described briefly. The central point of the model is calculation of the distribution function $f(\epsilon, t)$ of excimers in the collisionally mixed electronic states. Here $\epsilon$ is the vibrational energy and $t$ denotes time, the $\mathrm{B}$ and $\mathrm{C}$ electronic states are treated as a single state since collisional conversion of energy between these states has a rate about the rate of gas-kinetic collisions. For known $f$, the population of any vibrational level of state $B$ can be found as $n_{v}\left(\mathrm{~cm}^{-3}\right)=\frac{1}{2} f\left(\epsilon_{v}, t\right) \hbar \omega$, where $\epsilon_{v} \simeq \hbar \omega\left(v+\frac{1}{2}\right), \hbar \omega$ is the $\mathrm{KrF}(\mathrm{B})$ vibrational quantum. 


\section{V. DATSYUK}

The distribution function can be found for from the Fokker-Planck equation

$$
\frac{\partial f}{\partial t}+\frac{\partial}{\partial \epsilon} j(\epsilon, t)+\frac{1}{\tau_{u}} f=r(\epsilon, t)
$$

where $j \equiv-\frac{T \epsilon}{\tau_{v}}\left(\frac{\partial f}{\partial \epsilon}+\frac{f}{T}\right)$ is flow, $j(0, t)=0, \quad j(\epsilon \rightarrow$ $\infty, t)=0, \quad f(\epsilon, t \rightarrow-\infty)=0 ; \tau_{v}$ and $\tau_{u}$ are the times of vibrational relaxation and electronic deexcitation, respectively, $T$ is the temperature, $r$ is the pumping rate per unit of $\epsilon$. Rate $\tau_{u}^{-1}$ is the sum of the rates of radiation and collisional quenching.

The general solution of (1) is

$$
\begin{aligned}
f & =\frac{1}{T} \exp \left(-\frac{\epsilon}{T}\right) \\
& \times \exp \left(-\frac{t}{\tau_{u}}\right) \sum_{n=0}^{\infty} c_{n}(t) \exp \left(-n \frac{t}{\tau_{v}}\right) L_{n}\left(\frac{\epsilon}{T}\right),
\end{aligned}
$$

where $c_{n}(t)=\int_{-\infty}^{t} d t \exp \left((n+\kappa) \frac{t}{\tau_{v}}\right) \int_{0}^{D} d \epsilon r(\epsilon, t) L_{n}\left(\frac{\epsilon}{T}\right)$, $\kappa \equiv \tau_{v} / \tau_{u}, L_{n}$ is the Laguerre polynomial.

\section{THE LONG-TERM GAIN RECOVERY}

To study recovery of the gain coefficient $g(t)$ the following approximations are accepted in this paper

$$
\begin{aligned}
g(t) & =\sigma \int_{0}^{\infty} \vartheta_{1}(\epsilon) f(\epsilon, t) d \epsilon, \\
\vartheta_{1} & =\exp \left(-\frac{\epsilon}{\lambda_{1} \epsilon^{\prime}}\right)
\end{aligned}
$$

and

$$
\begin{aligned}
r(\epsilon, t) & =r_{0}(\epsilon)-\vartheta_{2}(\epsilon) \delta(t) \frac{\Delta N}{\epsilon^{\prime},} \\
\vartheta_{2} & = \begin{cases}\lambda_{2}\left(1-\epsilon / \epsilon^{\prime}\right)^{1-\lambda_{2}}, & 0<\epsilon<\epsilon^{\prime}, \\
0, & \epsilon>\epsilon^{\prime},\end{cases}
\end{aligned}
$$

where $\sigma$ is the stimulated emission cross section, $\epsilon^{\prime}=$ $n \hbar \omega, n$ is the number of vibrational levels available to laser transition ( $n=3$ according to [14] and $n=5$ according to $[13,15]), r_{0}(\epsilon)$ is the stationary pumping rate, $\Delta N$ is the number of excimers depopulated by a short pulse, $\lambda_{1}$ and $\lambda_{2}$ are surprising parameters (the rigorous way to introduce the surprising parameters is described for example, in $[18,19]$ ). The choice of equations (3) and (4) means that excimers on a few low vibrational levels contribute to light amplification and are depopulated by a short light pulse. The parameters $\lambda_{1}, \lambda_{2}$ seem to be about unity. Examples for the dependencies of $\vartheta_{1}$ and $\vartheta_{2}$ on $\epsilon$ are presented in Fig. 1.

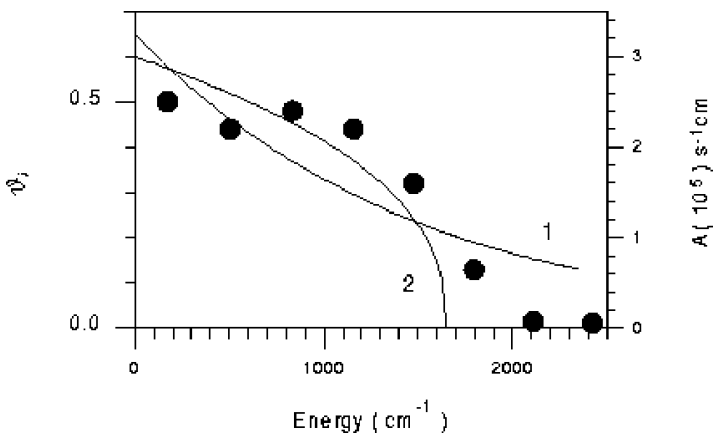

Fig. 1. Dependences $\vartheta_{1}(\epsilon)$ (curve 1 ) and $\vartheta_{2}(\epsilon)$ (curve 2 ) with $\epsilon^{\prime}=1650 \mathrm{~cm}^{-1}, \lambda_{1}=0.9, \lambda_{2}=0.6$. The filled circles are the spectral Einstein coefficients at $\lambda=248$ taken from Table 1 of [13].

On inserting term (4) into solution (2) we get

$$
\begin{aligned}
c_{n}(t) & =c_{n}^{(0)}+\Delta N F\left(-n, 1+\lambda_{2}, \frac{\epsilon^{\prime}}{T}\right), \\
g(t) & =g_{0}-\sigma \Delta N \exp \left(-t / \tau_{u}\right) S\left(1+\frac{T}{\lambda_{1} \epsilon^{\prime}}\right)^{-1},
\end{aligned}
$$

where

$$
\begin{aligned}
& S \equiv \sum_{n=0}^{\infty} F\left(-n, 1+\lambda_{2}, \frac{\epsilon^{\prime}}{T}\right) a^{n}, \\
& a \equiv \exp \left(-t / \tau_{v}\right)\left(1+\lambda_{1} \frac{\epsilon^{\prime}}{T}\right)^{-1},
\end{aligned}
$$

coefficients $c_{n}^{(0)}$ are attributed to the stationary pumping, $g_{0}$ is the net stationary small-signal gain coefficient (see Appendix A), $F$ is degenerate hypergeometric function of the first kind. According to the calculations presented in Appendix, the stationary gain coefficient $g_{0}$ depends on $\lambda_{1}$ weakly. Moreover, the same formula for $g_{0}$ has been obtained in $[16,17]$ for the Heavyside $\vartheta$-function used instead function (3).

Sum $S$ depends on parameters $\lambda_{1}, \lambda_{2}$ weakly too. To illustrate this dependence, we present $S$ in Table 1 for various values of $\lambda_{2}$. The values $\lambda_{2}=0,1$, and 2 correspond respectively to linearly increasing, constant, and decreasing dependences of $\vartheta_{2}$ on $\epsilon$. Because $\epsilon^{\prime} \gg T$ and therefore $a \ll 1$, the following approximation can be used for any moment of time

$$
S\left(1+\frac{T}{\lambda_{1} \epsilon^{\prime}}\right)^{-1} \simeq 1
$$


As follows from formula (5) with term (6), the longtime recovery of the gain can be described by the simple exponential low,

$$
g=g_{0}-\Delta g \exp \left(-t / \tau_{u}\right)
$$

where $\Delta g=\sigma \Delta N$. Thus, the time of the KrF gain recovery or the energy storage time $t_{s}$ equals the time of $\mathrm{KrF}^{*}$ electronic deexcitation $\tau_{u}$,

$$
t_{s}=\tau_{u}
$$

The value of $t_{s}$ is hence determined by excimer $\mathrm{B} \rightarrow$ $\mathrm{X}$ and $\mathrm{C} \rightarrow \mathrm{A}$ radiation and quenching collisions of excimers with atom and plasma electrons.

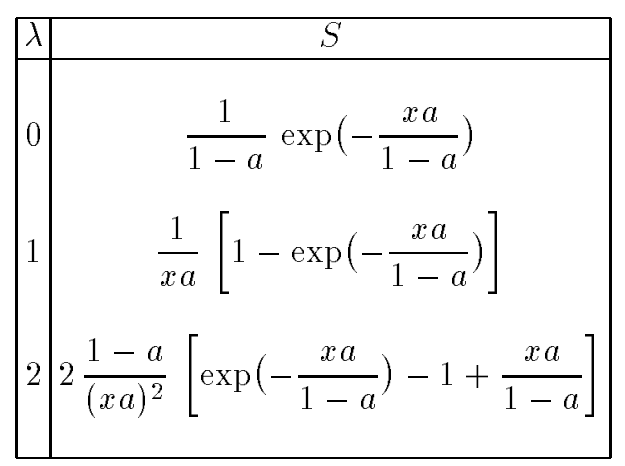

Table 1. Sum $S=\sum_{n=0}^{\infty} F(-n, 1+\lambda, x) a^{n}$.

\section{EXPERIMENTAL AND CALCULATED RECOVERY TIMES}

The time of the gain recovery $t_{s}$ has been measured for various electron-beam excited media. These data are presented in Table 2. To compare the theory with experimental data, corresponding values of $\tau_{u}$ have been calculated. Two sets of kinetic parameters have been used. Set I in Table 3 is taken from the tabulation of rate constants for the He-buffer electron-beam-excited $\mathrm{KrF}$ laser [12]. The numerous theoretical results obtained with these rate constants were in accord with experimental data [14-17]. An analogous set of parameters has also been used for the Ar-buffer electron-beam-excited laser

\begin{tabular}{|c|c|c|c|c|}
\hline \multirow[t]{2}{*}{$N$} & \multirow[t]{2}{*}{ Mixture composition } & \multirow{2}{*}{$\begin{array}{c}\text { measu- } \\
\text { red } t_{s}\end{array}$} & \multicolumn{2}{|c|}{ calculated $\tau_{u}$} \\
\hline & & & \begin{tabular}{|l|}
$\mathrm{I}$ \\
\end{tabular} & II \\
\hline 1 & $\begin{array}{l}6 \text { mbar } \mathrm{F}_{2}, 150 \text { mbar Kr, } \\
\text { and } \mathrm{He}^{a)}\end{array}$ & $1^{b)}$ & 1.8 & 2.6 \\
\hline 2 & $\begin{array}{l}5.5 \text { mbar } \mathrm{F}_{2}, 137.5 \text { mbar } \mathrm{Kr} \text {, } \\
550 \text { mbar } \mathrm{Ne} \text {, and } \mathrm{He}^{a} \text { ) }\end{array}$ & $1.8^{c)}$ & 2.2 & 2.7 \\
\hline 3 & $\begin{array}{l}4 \mathrm{mbar}_{2}, 110 \text { mbar } \mathrm{Kr} \\
70 \text { mbar } \mathrm{He}, \text { and } \mathrm{Ne}^{a)}\end{array}$ & $2.0^{c)}$ & 2.2 & 3.2 \\
\hline 4 & $\begin{array}{l}3 \text { torr } \mathrm{F}_{2}, 100 \text { torr } \mathrm{Kr} \\
\text { and } 500 \text { torr } \mathrm{Ar}\end{array}$ & $3^{d)}$ & 3.7 & 5.6 \\
\hline
\end{tabular}
[23].

Table 2. The measured energy storage times $t_{s}$ and the $\mathrm{KrF}^{*}$ lifetimes $\tau_{u}$ calculated with two sets of kinetic parameters. a) Total pressure $p=2.5$ bar; b) determined from Fig. 5 of Ref. [5] which represents experimental data of Ref. [4]; c) Ref. [6]; d) Ref. [7].

New kinetic parameters have been reported by Setser et al. [24]. Those were obtained from the observations of the $\mathrm{KrF}^{*}$ fluorescence decay. The new parameters are presented in Table 3 as set II. Note that even the effective radiative lifetimes of Sets I and II differ by a factor of two.

\begin{tabular}{|l|c|c|c|}
\hline \multirow{2}{*}{ Process } & \multicolumn{2}{|c|}{ Parameter } & \multirow{2}{*}{ Units } \\
\cline { 2 - 3 } & Set I & Set II & \\
\hline $\mathrm{KrF}^{*} \rightarrow \mathrm{KrF}+h \nu$ & 15.18 & 25 & $\mathrm{~ns}$ \\
$\mathrm{KrF}^{*}+\mathrm{F}_{2} \rightarrow \mathrm{Kr}+\mathrm{F}+\mathrm{F}_{2}$ & $7.8 \cdot 10^{-10}$ & $3.0 \cdot 10^{-10}$ & $\mathrm{~cm}^{3} / \mathrm{s}$ \\
$\mathrm{KrF}^{*}+2 \mathrm{Kr} \rightarrow \mathrm{KrF}_{2}^{*}+\mathrm{Kr}$ & $6.7 \cdot 10^{-31}$ & $6.0 \cdot 10^{-31}$ & $\mathrm{~cm}^{6} / \mathrm{s}$ \\
$\mathrm{KrF}^{*}+\mathrm{Kr}+\mathrm{Ar} \rightarrow \mathrm{KrF}+\mathrm{Ar}$ & $6.5 \cdot 10^{-31}$ & $5.5 \cdot 10^{-31}$ & $\mathrm{~cm}^{6} / \mathrm{s}$ \\
$\mathrm{KrF}^{*}+\mathrm{Kr}+\mathrm{He} \rightarrow \mathrm{F}+2 \mathrm{Kr}+\mathrm{He}$ & $5 \cdot 10^{-31 a)}$ & $4.6 \cdot 10^{-31}$ & $\mathrm{~cm}^{6} / \mathrm{s}$ \\
$\mathrm{KrF}^{*}+\mathrm{Kr}+\mathrm{Ne} \rightarrow \mathrm{F}+2 \mathrm{Kr}+\mathrm{Ne}$ & $5 \cdot 10^{-31 b)}$ & $4.9 \cdot 10^{-31}$ & $\mathrm{~cm}^{6} / \mathrm{s}$ \\
$\mathrm{KrF}^{*}+2 \mathrm{He} \rightarrow \mathrm{Kr}+\mathrm{F}+2 \mathrm{He}$ & $5 \cdot 10^{-32 a)}$ & neglected & $\mathrm{cm}^{6} / \mathrm{s}$ \\
$\mathrm{KrF}^{*}+2 \mathrm{Ne} \rightarrow \mathrm{Kr}+\mathrm{F}+2 \mathrm{Ne}$ & $5 \cdot 10^{-32 b)}$ & neglected & $\mathrm{cm}^{6} / \mathrm{s}$ \\
$\mathrm{KrF}^{*}+2 \mathrm{Ar} \rightarrow \mathrm{ArKrF}+\mathrm{Ar}$ & $7 \cdot 10^{-32}$ & neglected & $\mathrm{cm}^{6} / \mathrm{s}$ \\
$\mathrm{KrF}^{*}+\mathrm{Kr} \rightarrow 2 \mathrm{Kr}+\mathrm{F}$ & $2.0 \cdot 10^{-12}$ & $4.0 \cdot 10^{-12}$ & $\mathrm{~cm}^{3} / \mathrm{s}$ \\
$\mathrm{KrF}^{*}+\mathrm{Ar} \rightarrow \mathrm{Kr}+\mathrm{F}+\mathrm{Ar}$ & $1.8 \cdot 10^{-12}$ & $2.9 \cdot 10^{-12}$ & $\mathrm{~cm}^{3} / \mathrm{s}$ \\
$\mathrm{KrF}^{*}+\mathrm{He} \rightarrow \mathrm{Kr}+\mathrm{F}+\mathrm{He}$ & neglected & $2.5 \cdot 10^{-12}$ & $\mathrm{~cm}^{3} / \mathrm{s}$ \\
$\mathrm{KrF}^{*}+\mathrm{Ne} \rightarrow \mathrm{Kr}+\mathrm{F}+\mathrm{Ne}$ & neglected & $2.1 \cdot 10^{-12}$ & $\mathrm{~cm}^{3} / \mathrm{s}$ \\
\hline
\end{tabular}

Table 3. The radiative lifetime and the rate constants for $\mathrm{KrF}^{*}$ quenching by heavy particles. a) Ref. [21]; b) estimated value. 


\section{V. DATSYUK}

According to Table 2, the calculations of $\tau_{u}$ with the conventional set of parameters, (Set I), are in good agreement with the experimental data. The lifetimes found with the second set of parameters agree with measured $t_{s}$ worse. Both the calculations do not take into account the $\mathrm{KrF}^{*}$ quenching by plasma electrons. This quenching is characterized by the rate constant equal to $2 \cdot 10^{-7}$ $\mathrm{cm}^{3} / \mathrm{s}[1,22]$. For the typical electron density of $2 \cdot 10^{14}$ $\mathrm{cm}^{3} / \mathrm{s}[16,17]$, a theoretical value of $\tau_{u}$ equalling $2.5 \mathrm{~ns}$ should be reduced to $2.3 \mathrm{~ns}$. This nearly $10 \%$ reduction of the lifetime would lead to the excellent agreement of $\tau_{u}$ calculated with the conventional set of parameters with the measured $t_{s}$.

The measurements of [23] were fulfilled in pressure interval of 50 to 200 Torr. The $\mathrm{KrF}^{*}$ reactions with two buffer-gas atoms were therefore neglected. The threebody quenching is however important at high buffer gas pressure of 2.5 bar. Indeed, the three-body quenching rate constant of $5 \cdot 10^{-32} \mathrm{~cm}^{6} / \mathrm{s}$ would give a quenching rate of $2 \cdot 10^{8} \mathrm{~s}^{-1}$. This rate reduces the values of $\tau_{u}$ calculated with the second set by a factor of 2 . The reduction of $t_{s}$ will close the predictions of the second model to those of the first one. Thus, in accordance with the above notices, no discrepancies can be found between the values of $t_{s}$ measured and calculated with two sets of parameters.

\section{POPULATION OF UPPER LASER LEVEL}

The net small-signal gain coefficient can be related with the effective volume density $N_{a}$ of active molecules which contribute to the light amplification, $g=\sigma N_{a}$. For a stationary pumping

$$
r(\epsilon)=R \sum_{l} \beta_{l} \delta\left(\epsilon-\epsilon_{l}^{*}\right)
$$

where $\sum_{l} \beta_{l}=1$, we have according to Appendix 1 and $[16,17]$

$$
\begin{gathered}
N_{a}=\eta N \\
\eta=\sum_{l} \beta_{l} \eta_{l}, \quad \eta_{l}=\exp \left(-\tau_{v} \int_{\epsilon^{\prime}}^{\epsilon_{l}^{*}} \frac{d \epsilon}{\epsilon \tau_{u}}\right) .
\end{gathered}
$$

where $N=R \tau_{u}$ is the total volume density of electronically excited molecules, $\eta$ is the fraction of excited molecules which reach the low vibrational levels available for the laser transition.

Under nonstationary condition, the following formula for $d N_{a} / d t$ can be determined from (7)

$$
\frac{d N_{a}}{d t}=R \eta-\frac{N_{a}}{\tau_{u}}
$$

This equation describes population kinetics of the $\mathrm{KrF}$ upper laser level. It is clearly seen that due to kinetic processes in very high vibrational states, the rate of laserlevel pumping is lower than the excimer pumping rate by the quantity $\eta$. This factor was usually neglected in common computer models $[12,20]$.

\section{CONCLUSIONS}

The informative-theoretical analysis has been performed in order to understand the nanosecond gain dynamics in a KrF laser amplifier. It was shown that the effective population of the energy levels which contribute to the light amplification, $N_{a}$, can be calculated with Eq.(9). (Multiplication of $N_{a}$ by the stimulated emission cross section gives the net small signal gain coefficient.) In accordance with Eq. (9), the pumping rate of the upper laser level is lower than the rate of generation of excimers by a factor of $\eta$, Eq.(8).

The time of repumping of the upper laser level, determined by vibrational relaxation, equals the time of $\mathrm{KrF}^{*}$ deexcitation $\tau_{u}$. The calculations of $\tau_{u}$ with the conventional set of parameters $[12,16,17,14]$ are in accord with experimental data $[5-7]$. The use of the new parameters of [24] calls for the determination of the rate constants for the $\mathrm{KrF}^{*}$ quenching by two inert-gas atoms.

It was found that the process of vibrational relaxation in the region of low vibrational levels does not noticeably affect the gain dynamics.

\section{ACKNOWLEDGMENTS}

The work was supported by the INTAS grant 93-1103.

\section{APPENDIX A: SMALL-SIGNAL GAIN AT STATIONARY PUMPING}

This section presents details of calculation of the stationary net small-signal gain. Let us consider the stationary pumping of very high vibrational levels:

$$
r=R \delta\left(\epsilon-\epsilon^{*}\right)
$$

here $R$ is the pumping rate. Substituting (A1) into (2) one obtains the following expressions

$$
\begin{aligned}
c_{n}^{(0)}= & R \tau_{v} \frac{1}{n+\kappa} \exp \left((n+\kappa) \frac{t}{\tau_{v}}\right) L_{n}\left(\frac{\epsilon^{*}}{T}\right) \\
f_{0}(\epsilon) & =\frac{1}{T} \exp \left(-\frac{\epsilon}{T}\right) \\
& \times R \tau_{v} \sum_{n=0}^{\infty} \frac{1}{n+\kappa} L_{n}\left(\frac{\epsilon}{T}\right) L_{n}\left(\frac{\epsilon^{*}}{T}\right)
\end{aligned}
$$




$$
\sum_{n=0}^{\infty} \frac{1}{n+\kappa} L_{n}(x) L_{n}(y)=\Gamma(\kappa) F(\kappa, 1 ; x) G(\kappa, 1 ; y), \quad(x<y)
$$

where $F$ and $G$ are the degenerate hypergeometric functions of the first and the second kinds. At $\epsilon^{*} \gg T$, it can be applied the asymptotic formula for $G$ :

$$
G\left(\kappa, 1 ; \frac{\epsilon^{*}}{T}\right) \simeq\left(\frac{\epsilon^{*}}{T}\right)^{\kappa}
$$

Calculating the net small-signal gain coefficient with Eqs.(A2) and (3), we get

$$
g_{0}=\sigma R \tau_{v}\left(1+\frac{T}{\lambda_{1} \epsilon^{\prime}}\right)^{-1} S_{0}
$$

where

$$
S_{0} \equiv \sum_{n=0}^{\infty} \frac{1}{n+\kappa}\left(\frac{t}{t+1}\right)^{n} L_{n}\left(\frac{\epsilon^{*}}{T}\right)=\left(1+\frac{1}{t}\right)^{\kappa}\left[\Gamma(\kappa) G\left(\kappa, 1, \frac{\epsilon_{v}}{T}\right)-\int_{t \epsilon^{*} / T}^{\infty} d z z^{\kappa-1}\left(\frac{\epsilon^{*}}{T}+z\right)^{-\kappa} e^{-z}\right]
$$

where $t \equiv \frac{T}{\lambda_{1} \epsilon^{\prime}}$. At $\epsilon^{*} \gg \lambda_{1} \epsilon^{\prime}>T$, equation (A4) takes the following form

$$
S_{0}=\left(1+\frac{1}{t}\right)^{\kappa} \Gamma(\kappa) G\left(\kappa, 1 ; \frac{\epsilon^{*}}{T}\right)
$$

where $G$ can be expressed with Eq. (A3). If $\lambda_{1}$ be near unity and $\kappa<1$, the following approximation can be used

$$
\Gamma(1+\kappa)(1+t)^{\kappa-1} \lambda_{1}^{\kappa} \simeq 1
$$

Equation (A4) can hence be written as follows

$$
g_{0}=\sigma R \tau_{u} \eta, \quad \eta=\exp \left(-\tau_{v} \int_{\epsilon^{\prime}}^{\epsilon^{*}} \frac{d \epsilon}{\epsilon \tau_{u}}\right)
$$

The same formula has been obtained in $[16,17]$ with the Heavyside function used in equation (3)

$$
\vartheta\left(\epsilon-\epsilon^{\prime}\right)=\left\{\begin{array}{l}
1, \epsilon \leq \epsilon^{\prime} \\
0, \epsilon>\epsilon^{\prime}
\end{array}\right.
$$

[1] Applied Atomic Collision Physics, Vol. 3, Gas Lasers, edited by E. W. McDaniel, W. L. Nighan (Academic Press, New York, 1982).

[2] The first, picosecond, stage of the gain recovery has been studied elsewhere [3-8].

[3] P. B. Corkum, R. S. Taylor, IEEE J. Quantum Electron. QE-18, 1962 (1982).

[4] S. Szatmari, F. P. Schäfer, Appl. Phys. B 33, 219 (1984).
[5] S. Szatmari, F. P. Schäfer, J. Opt. Soc. Am. B 4, 1943 (1987).

[6] A. J. Taylor, R. B. Gibson, J. P. Roberts, Appl. Phys. Lett. 52, 773 (1988).

[7] J. R. M. Barr, N. J. Everall, C. J. Hooker, I. N. Ross, M. J. Shaw, W. T. Toner, Opt. Commun. 66, 127 (1988). [8] S. Szatmari, Top. Appl. Phys. 70, 129 (1992).

[9] O. L. Bourne, A. J. Alcock, Appl. Phys. B 32, 193 (1983). 


\title{
V. V. DATSYUK
}

[10] V. V. Datsyuk, I. A. Izmailov, V. A. Kochelap, Opt. Spektroskop. 69, 802 (1990); Opt. Spectroskop. 69, 477 (1990).

[11] The typical relation between $\tau_{v}$ and $\tau_{u}$ is $\tau_{v}=0.3 \tau_{u}$.

[12] F. Kannari, M. Obara, T. Fujioka, J. Appl. Phys. 57, 4309 (1985).

[13] W. L. Morgan, N. W. Winter, K. C. Kulander, J. Appl. Phys. 54, 4275 (1983).

[14] Y.-W. Lee, A. Endoh, Appl. Phys. B 52, 245 (1991).

[15] F. Kannari, M. J. Shaw, F. O’Neill, J. Appl. Phys. 61, 476 (1987).

[16] V. V. Datsyuk, I. A. Izmailov, V. A. Kochelap, Kvant. Elektron. (Moscow) 15, 106 (1988) [Sov. J. Quantum Electron. 18, 67 (1988)].

[17] V. V. Datsyuk, Appl. Phys. B 55, 60 (1992).
[18] I. Procaccia, R. D. Levine, J. Chem. Phys. 63, 4261 (1975).

[19] T. D. Dreiling, D. W. Setser, J. Chem. Phys. 75, 4360 (1981).

[20] V. V. Datsyuk, I. A. Izmailov, V. A. Kochelap, Usp. Fiz. Nauk 168, 439 (1998) [Sov. Phys. Usp. 41, 379 (1998)].

[21] A. E. Green, C. A. Brau, IEEE J. Quantum Electron. QE-14, 951 (1978).

[22] E. C. Harvey, C. J. Hooker, M. H. Key, A. K. Kidd, J. M. D.Lister, M. J. Shaw, W. T. Leland, J. Appl. Phys. 70, 5238 (1991).

[23] M. J. Shaw, Appl. Phys. B 30, 5 (1983).

[24] J. Xu, W. Gadomski, D. W. Setser, J. Chem. Phys. 99, 2591 (1993).

\section{ІНФОРМАЦІӤНО-ТЕОРЕТИЧНИЙ АНАЛІЗ НАНОСЕКУНДНОЇ ДИНАМІКИ КОЕФІЩІЕНТА ПІДСИЛЕННЯ СВІТЛА В ЛАЗЕРНОМУ ПІДСИЛЮВАЧІ НА КrF}

\author{
В. В. Дапюк \\ Кийвсъкий університет імені Тараса ІІІевченка, фізичний факультет, \\ вул. Володимирсвка, 64, Киӥв, 01033, Украӥна
}

\begin{abstract}
Праця розвиває теорію коливальної релаксапії ексимерних молекул у $\mathrm{KrF}$ лазері. Змодельовано динаміку заселення верхнього лазерного рівня після проходження через активне середовище короткого світлового імпульсу, що насичує лазерний підсилювач. Особливістю лазера на $\mathrm{KrF} \epsilon$ те, що внесок у підсилення світла дають декілька нижніх коливних рівнів молекули $\mathrm{KrF}(\mathrm{B})$. Заселеності цих рівнів обчислено за допомогою рівняння Фоккера-Планка. Однак параметри цього диференційного рівняння не $є$ певно визначеними. Тому у праці застосовано інформаційно-теоретичний аналіз. Такий підхід дозволив знайти наочний закон зміни коефіпієнта підсилення світла, який може бути перевірений експериментально. Отримано формули для параметрів знайденого рівняння: внутрішньої ефективности заселення верхнього лазерного рівня та часу ві,дновлення коефіпієнта підсилення світла. Побудована кінетична модель добре узгоджується як з результатами експериментів, так і з іншими теоретичними дослідженнями - однаково і при розв'язку динамічної задачі, і в квазістаціонарних умовах.
\end{abstract}

